Polymer Journal, Vol. 39, No. 9, pp. 953-960 (2007)

(C) 2007 The Society of Polymer Science, Japan

\title{
Development of Oriented Morphology and Mechanical Properties upon Drawing of Stereo-Complex of Poly(L-lactic acid) and Poly(D-lactic acid) by Solid-State Coextrusion
}

\author{
Daisuke SAWAI, ${ }^{1, \dagger}$ Masanori TAMADA, ${ }^{1}$ and Tetsuo KANAMOTO ${ }^{1}$ \\ ${ }^{1}$ Department of Applied Chemistry, Tokyo University of Science, \\ 12-1 Ichigaya-Funagawara, Shinjuku-ku, Tokyo 162-0826, Japan
}

(Received May 9, 2007; Accepted June 15, 2007; Published July 24, 2007)

\begin{abstract}
A semicrystalline film consisting of only stereo-complex (sc) crystals was prepared by casting from a solution of an equimolar blend of poly(L-lactic acid) (PLLA) and poly(D-lactic acid) (PDLA). The film was uniaxially drawn by solid-state coextrusion, and the development of oriented morphology and mechanical properties was investigated by DSC, WAXD, dynamic mechanical analyses and tensile tests. The ductility increased with extrusion temperature $\left(T_{\text {ext }}\right)$, reached a maximum at a $T_{\text {ext }}$ of $200{ }^{\circ} \mathrm{C}$, and at yet higher $T_{\text {ext }}$ 's it rapidly decreased. The maximum tensile modulus and strength of $9.5 \mathrm{GPa}$ and $410 \mathrm{MPa}$, respectively, were achieved for a highly drawn sc-film prepared by coextrusion at a $T_{\text {ext }}$ of $200{ }^{\circ} \mathrm{C}$ and EDR of 16 . Such a drawn film consisted of highly oriented sc-crystals and had a crystallinity of $\chi_{\mathrm{c}}=59 \mathrm{wt} \%$ and a high chain orientation function of $f_{\mathrm{c}}=0.993$. The oriented sc-films exhibited remarkably enhanced heat-resistance compared to the oriented films of PLLA homo-polymer. The dynamic storage modulus of a sc-film with an EDR of 16 , measured at $11 \mathrm{~Hz}$, was $9.5 \mathrm{GPa}$ at room temperature and $2.7 \mathrm{GPa}$ even at $200^{\circ} \mathrm{C}, 20$ $25^{\circ} \mathrm{C}$ above the melting temperatures of $\alpha$ - and $\beta$-form homo-crystals. The high thermal stability of oriented sc-films was primarily ascribed to the high melting temperature and weak $\alpha$-relaxation intensity for the sc-films compared to the PLLA films. No existence of a crystalline relaxation in the sc-films also contributed to improve their thermal stability. [doi:10.1295/polymj.PJ2007038]

KEY WORDS Drawing / Stereo-Complex of PLLA and PDLA / Oriented Morphology / Mechanical Properties / High Thermal Stability /
\end{abstract}

Poly(L-lactic acid) (PLLA) attracts considerable interest from both fundamental and industrial viewpoints because it can be synthesized from renewable resources, such as corn and potato. ${ }^{1-3}$ Since PLLA is biodegradable and biocompatible, this polymer has been used for biomedical applications. ${ }^{4-6}$ Because PLLA has fairly good mechanical properties with a high melting temperature $\left(T_{\mathrm{m}}=170-180^{\circ} \mathrm{C}\right)$, its application for more general purposes as an environmentally friendly and economically feasible polymer has been evaluated. ${ }^{7-9}$

PLLA commonly crystallizes into two crystal modifications; i.e., the $\alpha$ - and the $\beta$-forms, ${ }^{10-12}$ both of which have a melting temperature around 170$180^{\circ} \mathrm{C}$. It has been reported that an equimolar blend of PLLA and poly(D-lactic acid) (PDLA) forms a mixture of stereo-complex crystals and $\alpha$-form homocrystals when it was crystallized from solutions and melt, depending on the crystallization conditions. ${ }^{13,14}$ Homo-crystals, such as $\alpha$-form and $\beta$-form crystals consist of only PLLA or PDLA molecules, whereas the sc-crystal is composed of PLLA and PDLA chains with opposite helical hand packed side by side. It is interesting to note that the sc-crystal shows a melting temperature of $220-230^{\circ} \mathrm{C}$, which is about $50-60^{\circ} \mathrm{C}$ higher than those for the homo-crystals. Recently, Kimura et al. ${ }^{15,16}$ found bacteria which produces Dlactic acid from glucose. This finding may allow to produce D-lactic acid more easily at a lower coast and enhance the application of sc-poly(lactic acid).

It has been reported that when an equimolar blend of PLLA and PDLA was cast from solutions, sc-crystals formed more efficiently for low molecular weight samples, ${ }^{17}$ and the formation depended on the solvent species used, and the rates of solvent evaporation and stirring the solution. ${ }^{17,18}$ Furthermore, it was difficult to prepare a highly crystalline sample consisting of sc-crystals alone from a blend of high molecular weights PLLA and PDLA. These facts show that the diffusion of polymer segments and collision frequency between PLLA and PDLA segments are important factors for the formation of sc-crystals.

Mechanical properties of sc-samples have been reported by a few authors. ${ }^{19-21}$ Takasaki et al. ${ }^{19}$ succeeded in the preparation of sc-fibers by high-speed melt spinning of an equimolar blend of PLLA and PDLA. Their oriented sc-fiber had a crystallinity $\chi_{c}{ }^{s c}$ of $\sim 37 \mathrm{wt} \%$ and showed tensile modulus and strength of $4.0 \mathrm{GPa}$ and $200 \mathrm{MPa}$, respectively, which were slightly lower than those found in fibers consisting 
of a mixture of sc-crystals and homo-crystals such as $\alpha$-form and $\beta$-form crystals. Yamane et al. ${ }^{20}$ prepared oriented sc-fibers $\left(\chi_{\mathrm{c}}^{\mathrm{sc}}\right.$ of $\left.38-40 \mathrm{wt} \%\right)$ by melt spinning of amorphous fibers of an equimolar blend of PLLA and PDLA, followed by drawing at 60$120^{\circ} \mathrm{C}$ and subsequent annealing at $170-200^{\circ} \mathrm{C}$, which were above the melting temperature range of homo-crystals but below the melting temperature of a sc-crystal. Their strongest sc-fiber had a tensile modulus and strength of $4.7 \mathrm{GPa}$ and $335 \mathrm{MPa}$, respectively. We also have reported that the maximum achieved tensile modulus and strength of an oriented sc-film prepared by solid-state coextrusion (SSCE) ${ }^{21}$ of a solvent cast film of an equimolar blend of PLLA and PDLA, which consisted mainly of $\alpha$-form crystals at a $T_{\text {ext }}=200{ }^{\circ} \mathrm{C}$, were $5.0 \mathrm{GPa}$ and $130 \mathrm{MPa}$, respectively. ${ }^{21}$ It was found that enhanced development of sc-crystals does not necessarily lead to the formation of fibers with excellent mechanical properties. ${ }^{19,22}$ Some sc-crystal rich fibers showing tensile modulli of $6.0-8.6 \mathrm{GPa}$ and strength of $580-920 \mathrm{MPa}$ were obtained by high speed spinning ${ }^{19}$ and dry spinning followed by hot drawing. ${ }^{20,22}$

In this article, we report on the development of oriented morphology and mechanical properties upon drawing of solvent cast films consisted of randomly oriented sc-crystals. The draw was made by using a SSCE technique, since it was also found that the formation of sc-crystals proceeded more efficiently for SSCE than for tensile drawing. ${ }^{21}$ The improved heat resistance of the oriented sc-films is also emphasized.

\section{EXPERIMENTAL SECTION}

\section{Samples}

PLLA and PDLA samples were used after removal of the oligomer and the polymerization catalyst (stannous octoate). The PLLA used had a weight-average molecular weight, $M_{\mathrm{w}}$, of $7.1 \times 10^{4}$ and a numberaverage molecular weight, $M_{\mathrm{n}}$, of $3.4 \times 10^{4}$ and the PDLA had $M_{\mathrm{w}}=2.3 \times 10^{5}$ and $M_{\mathrm{n}}=1.4 \times 10^{5}$. The specific optical rotation measured in chloroform at $25^{\circ} \mathrm{C}$ and a wave length of $589 \mathrm{~nm}\left([a]_{\mathrm{D}}\right)$ was -154 and $+155^{\circ}$, respectively, for the PLLA and PDLA, suggesting that the optical purity of both of these samples was $99.5 \% .{ }^{18}$ Before the preparation of polymer solution, the samples were dried in vacuo at $100^{\circ} \mathrm{C}$ for $24 \mathrm{~h}$. Each polymer solution of PLLA and PDLA of $1 \mathrm{wt} \%$ was separately prepared by dissolving a requisite amount of the polymer in chloroform at room temperature. They were admixed with each other with vigorously stirring to prepare a solution of an equimolar blend of PLLA and PDLA. The solution was cast onto a Petri dish, covered with an aluminum foil having holes, followed by solvent evaporation at room temperature for approximately $3 \mathrm{~h}, 10 \mathrm{~h}$ and $7 \mathrm{~d}$ by controlling the evaporation rate of the solvent. ${ }^{17}$ The rate of the solvent evaporation, which was continuously monitored by measuring the weight of the Petri dish containing the solution, was controlled by adjusting the number of holes and their sizes. These films were abbreviated as $3 \mathrm{~h}$-film, $10 \mathrm{~h}$ film, and $7 \mathrm{~d}$-film, respectively. They were drawn after drying in vacuo at $100^{\circ} \mathrm{C}$ for $20 \mathrm{~h}$.

\section{Drawing}

Draw was made by SSCE, ${ }^{23}$ since sc-crystals were produced more efficiently by this technique than for the tensile drawing as reported in our previous work. ${ }^{21}$

For SSCE, a strip $10 \mathrm{~mm}$ wide and $70 \mathrm{~mm}$ long was placed between split billet halves of poly(4-methyle1-pentene) (P4M1P) and the assembly was coextruded through a conical brass die. The extrusion rate was $\sim 1 \mathrm{~cm} / \mathrm{min}$ independently of the extrusion draw ratio (EDR).

\section{Characterization}

The $M_{\mathrm{w}}$ and $M_{\mathrm{n}}$ of the poly(lactic acid)s were determined by GPC using chloroform solvent at $40^{\circ} \mathrm{C}$ on a Waters GPC system with Shodex gel columns (GPC LF-804 $\times 2$ ). The molecular weight calibration was made by using narrow-distribution polystyrene standards. One wt \% solutions of these polymers were prepared by dissolving requisite amounts of them in chloroform at room temperature for $1 \mathrm{~d}$ in sealed test tubes.

The specific optical rotations $([\alpha])$ of the polymers were measured in chloroform at a concentration of $1 \mathrm{~g} / \mathrm{dL}$ and $25^{\circ} \mathrm{C}$ using a JASCO Co. digital polarimeter DIP-370 at a wavelength of $589 \mathrm{~nm}$.

The melting temperature $\left(T_{\mathrm{m}}\right)$ and heat of fusion $(\Delta H)$ of samples were determined on a SEIKO DSC-220C differential scanning calorimeter (DSC) at a heating rate of $10^{\circ} \mathrm{C} / \mathrm{min}$ under a $\mathrm{N}_{2}$ gas flow. $T_{\mathrm{m}}$ and $\Delta H$ were calibrated by using an indium standard. The crystallinity of a sample was determined by the ratio of the observed $\Delta H$ to the heat of fusion for a perfect crystal, $\Delta H_{\mathrm{c}}$. The $\Delta H_{\mathrm{c}}$ for the $\alpha-, \beta-$, and sc-crystals were assumed to be $94,{ }^{24} 124,{ }^{11}$ and $155 \mathrm{~J} / \mathrm{g},{ }^{25}$ respectively.

Wide-angle X-ray diffraction (WAXD) photographs were recorded by using a flat plate camera with $\mathrm{Cu} \mathrm{K} \alpha$ radiation generated at $40 \mathrm{kV}$ and $25 \mathrm{~mA}$ on a Rigaku Geigerflex RAD-3A and monochromatized with a graphite crystal. The diffraction profiles were recorded with $\mathrm{Ni}$-filtered $\mathrm{Cu} \mathrm{K} \alpha$ radiation generated at $50 \mathrm{kV}$ and $300 \mathrm{~mA}$ on a Rigaku Ultrax 18 equipped with a diffractometer and a pulse height discriminator. Crystalline chain orientation was evaluated by the Herman orientation function, $f_{\mathrm{c}} \cdot{ }^{26}$ The $f_{\mathrm{c}}$ was evaluat- 
ed from the azimuthal intensity distribution of the (100) reflection of the sc-crystals assuming a fiber symmetry. The azimuthal intensity distribution was recorded by step scans at $0.1^{\circ}$ intervals in azimuthal angle, using a Rigaku fiber specimen holder with a first collimator of $\phi=0.5 \mathrm{~mm}$ and a receiving slit of $1.8^{\circ}(2 \theta$ direction $) \times 0.3^{\circ}$ (azimuthal direction).

Dynamic mechanical analysis (DMA) was made on an Orientec Rheovibron DDV-II-EP viscoelastomer operated at a frequency of $11 \mathrm{~Hz}$ and at a heating rate of $2{ }^{\circ} \mathrm{C} / \mathrm{min}$.

The tensile modulus and strength on the fiber axis were measured at strain rates of $1 \times 10^{-3}$ and $1 \times$ $10^{-2} \mathrm{~s}^{-1}$, respectively, at room temperature. The measurements were made at least five times for a given sample. The modulus was determined from the initial slope of the stress/strain curve at low strain $(<0.1 \%)$. The cross section of a film was calculated from the density, weight and length of the sample. The sample length along the test direction was 100 200 and $30 \mathrm{~mm}$ for the measurements of tensile modulus and strength, respectively.

\section{RESULTS AND DISCUSSION}

In a previous work, ${ }^{21}$ we prepared oriented films consisting of only sc-crystals by SSCE at $200{ }^{\circ} \mathrm{C}$ of a film of an equimolar blend of PLLA and PDLA, which was consisted predominantly of $\alpha$-form crystals and a small amount of sc-crystals. The mechanical properties for the oriented sc-films prepared at a high temperature $\left(200^{\circ} \mathrm{C}\right)$ were significantly lower than those for the oriented films prepared at a lower temperature around $170{ }^{\circ} \mathrm{C}$, slightly below the $T_{\mathrm{m}}$ of the homo-crystals, due to the lower crystallinity and poor chain orientation for the former. It was also found that the formation of sc-crystals proceeded more efficiently for the SSCE than for the tensile drawing at elevated temperatures between the $T_{\mathrm{m}}$ 's of homo-crystals (170-180 ${ }^{\circ} \mathrm{C}$ for $\alpha$ - and $\beta$-crystals) and the $T_{\mathrm{m}}$ of sccrystal $\left(220-230^{\circ} \mathrm{C}\right)$, producing oriented films with a higher crystallinity and higher chain orientation. In this work, therefore, sc-films consisting of randomly oriented sc-crystals alone were drawn by SSCE.

Figure 1 shows DSC thermograms and WAXD photographs of PLLA/PDLA cast films prepared by controlling the evaporation rate of solvent from the solution. The formation of crystal modifications in the solvent cast PLLA/PDLA films was significantly influenced by the evaporation rate of the solvent as reported by Tsuji et al. ${ }^{18}$ The PLLA/PDLA films prepared at higher evaporation rates commonly consisted of a mixture of $\alpha$ - and sc-form crystals. Both the amount and the fraction of sc-crystals increased with decreasing the evaporation rate of the solvent, and a

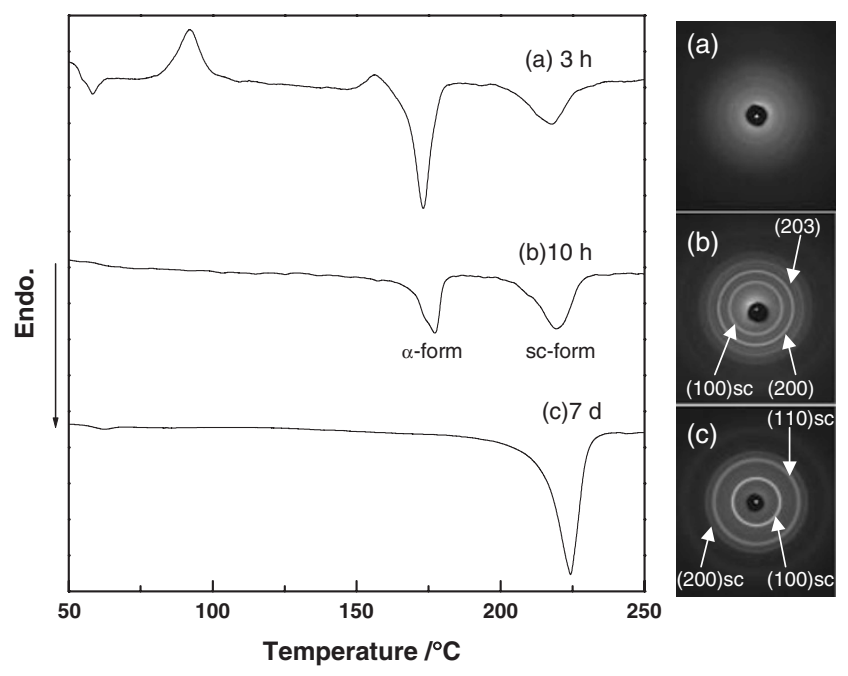

Figure 1. DSC thermograms and WAXD photographs for solvent-cast films of an equimolar blend of PLLA and PDLA, prepared at various evaporation times, (a) $3 \mathrm{~h}$, (b) $10 \mathrm{~h}$, (c) $7 \mathrm{~d}$. DSC heating rate was $10^{\circ} \mathrm{C} / \mathrm{min}$.

film consisting of only sc-crystals (sc-films) was obtained by slowly evaporating the solvent for $7 \mathrm{~d}$. Such a sc-film had a crystallinity of $44-47 \mathrm{wt} \%$, as estimated from the $\Delta H_{\mathrm{f}}$ of the sample assuming that the $\Delta H_{\mathrm{f}}$ of a perfect sc-crystal was $155 \mathrm{~J} / \mathrm{g} .{ }^{25}$ The sc-film prepared by evaporating the solvent for $7 \mathrm{~d}$ was chosen as the starting material for the drawing by SSCE, because oriented films with high sc-crystal contents (crystallinity) and high chain orientation were obtained as compared to the drawing of the films which were prepared at rapid evaporation rates.

Figure 2 shows the maximum achieved EDR $\left(\mathrm{EDR}_{\max }\right)$ as a function of extrusion temperature $\left(T_{\text {ext }}\right)$ for SSCE of the sc-film. The ductility increased

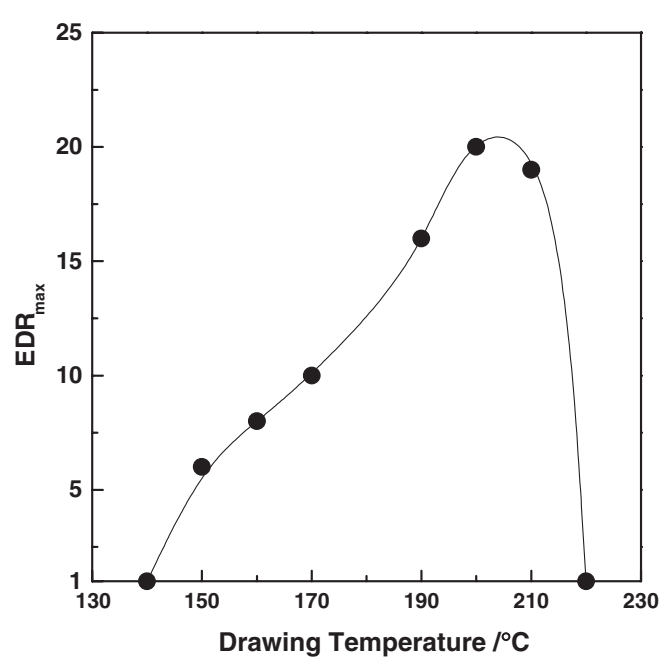

Figure 2. Maximum achieved extrusion draw ratio $\left(\mathrm{EDR}_{\max }\right)$ as a function of drawing temperature $\left(T_{\text {ext }}\right)$ for solid-state coextrusion of a sc-film ( $7 \mathrm{~d}$-film) consisting of sc-crystals alone. 


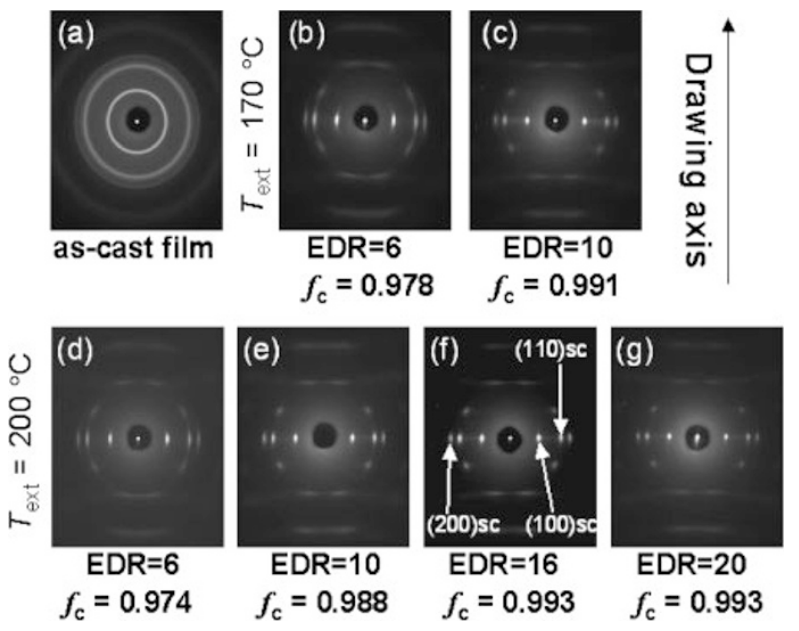

Figure 3. WAXD photographs of the starting sc-film (7dfilm) and EDR series prepared by SSCE at $T_{\text {ext }}$ 's $=170{ }^{\circ} \mathrm{C}$ (top) and $200^{\circ} \mathrm{C}$ (bottom).

with $T_{\text {ext }}$ above $T_{\text {ext }}>140^{\circ} \mathrm{C}$, reaching a maximum $(\mathrm{EDR} \cong 20)$ at a $T_{\mathrm{ext}}$ around $200^{\circ} \mathrm{C}$. At yet higher $T_{\text {ext }}$ 's, SSCE was possible but the drawn product partially melted after coming out of the extrusion die, and no uniform extrudates could be obtained.

Figure 3 shows WAXD photographs for the as-cast $7 \mathrm{~d}$-film and two EDR series prepared by SSCE of the cast film at $T_{\text {ext }}$ s $s=170$ and $200^{\circ} \mathrm{C}$. The patterns taken with the incident X-Ray beam both parallel and perpendicular to the film surface were identical. The initial cast-film (Figure 3a) showed Debye-Scherrer rings at around $2 \theta=11.8,21.1$ and $24.6^{\circ}$, which were assigned to the (100), (110), and (200) reflections of the sc-crystals, and no reflections from $\alpha$-form crystals were observed. With increasing EDR, the reflections became gradually sharper, and the azimuthal intensity distribution concentrated on the equator. Fairly high chain orientation was indicated by the sharp and circular reflection spots on the equator for the films with EDRs $=16$ (Figure 3f) and 20 (Figure 3g) prepared at a $T_{\mathrm{ext}}=200^{\circ} \mathrm{C}$. The chain orientation of the sccrystals along the fiber axis, evaluated by the Herman orientation function, $f_{\mathrm{c}},{ }^{26}$ was 0.993 for the drawn films with $\mathrm{EDR}=16$ (Figure 3c) and 20 (Figure 3d) prepared at $200^{\circ} \mathrm{C}$. To the best of our knowledge, no such a high chain orientation has been reported for oriented sc-films consisting of sc-crystals alone.

It is interesting to remember that an oriented sc-film with an EDR of 30, prepared by SSCE at $200^{\circ} \mathrm{C}$ of a cast film which was prepared from a $1 \mathrm{wt} \%$ solution of an equmolar blend of high $M_{\mathrm{w}}$ PLLA and PDLA in dichloromethane and consisted predominantly of $\alpha$-form crystals and a small amount of sc-crystals, showed poor chain orientation of $f_{\mathrm{c}}=0.96 .{ }^{21}$ This low efficiency of draw was ascribed to the melting of $\alpha$-form crystals and the deformation proceeded in
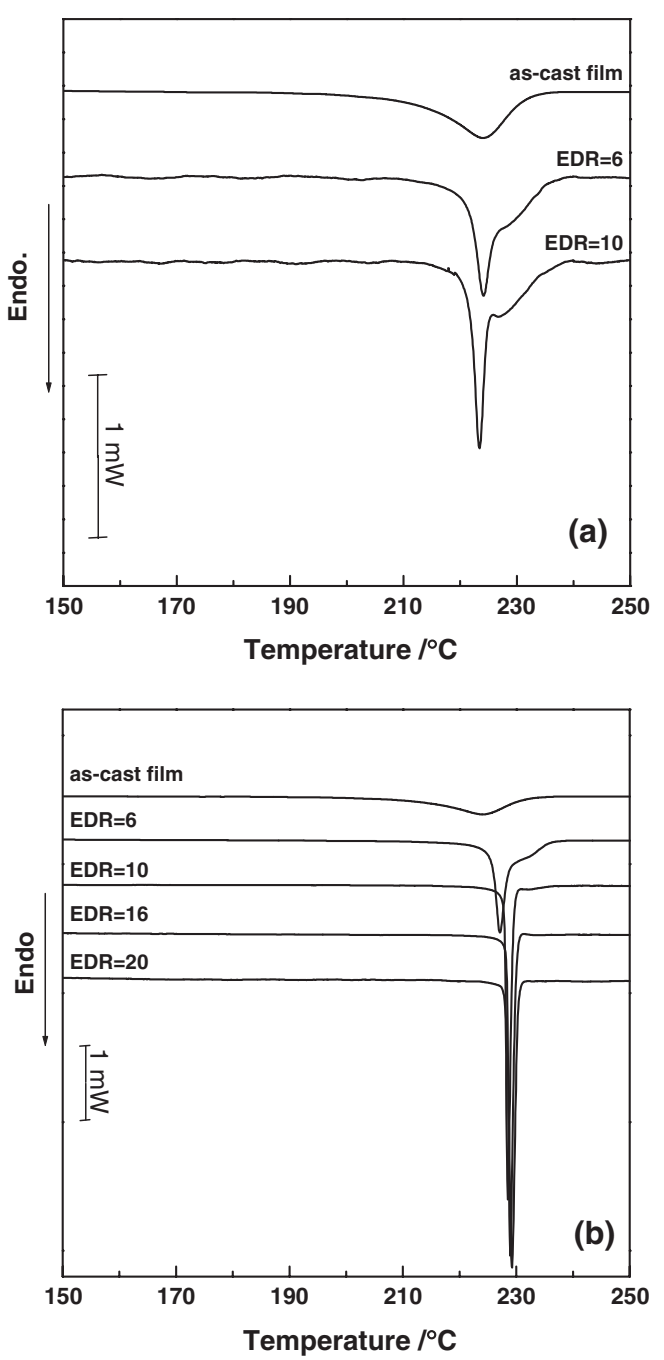

Figure 4. DSC theromograms of a sc-film and EDR series prepared by SSCE at $T_{\text {ext }}$ 's $=170^{\circ} \mathrm{C}$ (a) and $200^{\circ} \mathrm{C}$ (b). DSC heating rate was $10^{\circ} \mathrm{C} / \mathrm{min}$.

an almost molten state during the SSCE.

Figure 4 shows DSC thermograms for EDR series prepared by SSCE of a $7 \mathrm{~d}$-film at $T_{\text {ext }}$ 's below $\left(170^{\circ} \mathrm{C}\right)$ and above $\left(200^{\circ} \mathrm{C}\right)$ the $T_{\mathrm{m}}$ of homo-crystals $\left(\sim 180^{\circ} \mathrm{C}\right)$. The starting cast film showed a single and broad endothermic peak around $223{ }^{\circ} \mathrm{C}$ due to the melting of sc-crystals. Upon SSCE of the film at a $T_{\text {ext }}$ of $170^{\circ} \mathrm{C}$, a sharp melting peak at $223^{\circ} \mathrm{C}$ and a shoulder at a higher temperature side of this peak grew at the expense of the low temperature shoulder of the broad melting peak for the cast film, reflecting the deformation of the initial sc-crystals as shown in Figure 3. For the SSCE at a $T_{\text {ext }}$ of $200^{\circ} \mathrm{C}$ and a low EDR of 6, a sharp peak at $226^{\circ} \mathrm{C}$ overlapped with a shoulder at high temperature side developed. This peak shifted slightly higher with increasing EDR and reached at $229^{\circ} \mathrm{C}$ for the highest EDR of 20 achieved. At EDRs $\geq 10$, no shoulder appeared at higher temperature side of the melting peak. It is noted that all the crystals existed in the highly drawn film 


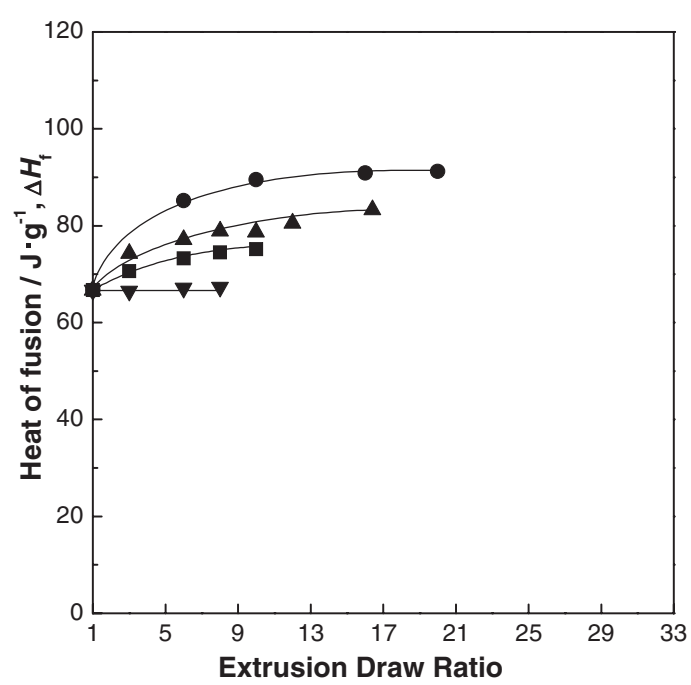

Figure 5. Heat of fusion of sc-crystals as a function of the EDR for drawn samples prepared by SSCE at $T_{\text {ext }}=160^{\circ} \mathrm{C}$ $(\boldsymbol{\nabla}), 170^{\circ} \mathrm{C}(\boldsymbol{\square}), 190^{\circ} \mathrm{C}(\mathbf{\Delta})$, and $200^{\circ} \mathrm{C}(\bullet)$.

with an $\mathrm{EDR}=20$ melt below $230^{\circ} \mathrm{C}$, whereas a drawn film with a low EDR of 6 showed a melting tail extended up to about $235^{\circ} \mathrm{C}$. These facts suggest that the structural reorganization during DSC heating proceeded more rapidly for the sample with a lower EDR, which consisted of partially destructed and metastable sc-crystals, and therefore the structural reorganization rapidly took place during the DSC heating process. In contrast, the crystallites existed in a highly drawn sample, prepared at a higher $T_{\text {ext }}$ of $200^{\circ} \mathrm{C}$, were more stable than the initial crystals and they were constrained by the noncrystalline chains which connected the oriented crystallites in a microfibril. Therefore, the structural reorganization of the highly drawn samples during DSC heating was suppressed.

The $\Delta H_{\mathrm{f}}$ of sc-crystals for series of drawn samples were determined from the DSC thermograms. Figure 5 shows $\Delta H_{\mathrm{f}}$ as a function of EDR for the SSCE of a cast film ( $7 \mathrm{~d}$-film) consisting of sc-crystals alone in the $T_{\text {ext }}$ range of $160-200^{\circ} \mathrm{C}$. The cast film showed a $\Delta H_{\mathrm{f}}$ of $67 \mathrm{~J} / \mathrm{g}$. For drawing the film at a $T_{\text {ext }}=160^{\circ} \mathrm{C}$, the $\Delta H_{\mathrm{f}}$ stayed at a constant value of $67 \mathrm{~J} / \mathrm{g}$, independently of the EDR. For drawing at a higher $T_{\text {ext }}$, however, the $\Delta H_{\mathrm{f}}$ increased with EDR, with this tendency more prominent at higher $T_{\text {ext }}$ 's. Thus, for the SSCE at $200^{\circ} \mathrm{C}$ to the maximum EDR of 21 , a highly oriented sample $\left(f_{\mathrm{c}}=0.993\right)$ showing the highest $\Delta H_{\mathrm{f}}$ of $91 \mathrm{~J} / \mathrm{g}$ was obtained. Such a $\Delta H_{\mathrm{f}}$ is the highest among ever reported before (50-85 $\left.\mathrm{J} / \mathrm{g}^{19-21}\right)$. The $\Delta H_{\mathrm{f}}$ of $91 \mathrm{~J} / \mathrm{g}$ corresponds to a crystallinity of 59-64 wt \%, depending on the values of 143 $\mathrm{J} / \mathrm{g}^{27}-155 \mathrm{~J} / \mathrm{g}^{25}$ for the heat of fusion of a perfect sccrystal. These facts indicate that for SSCE at a low $T_{\text {ext }}$, the sc-crystals existed within the starting cast film were deformed and oriented, but no further crys-

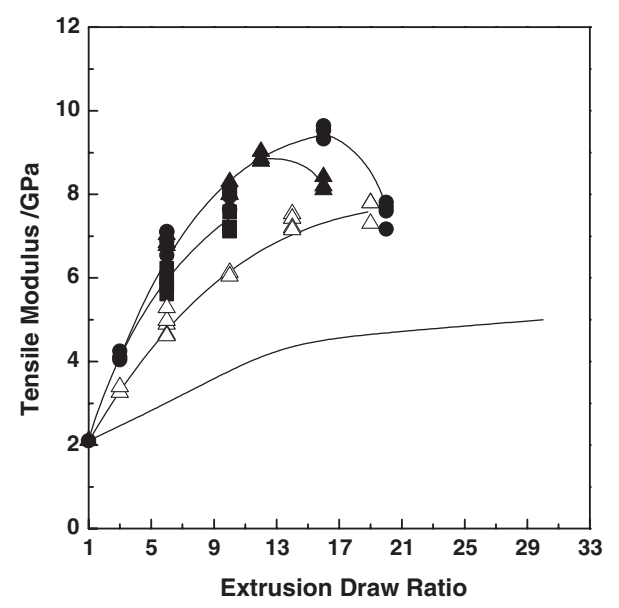

Figure 6. Tensile modulus as a function of EDR for SSCE of a sc-film (7 d-film) at various $T_{\text {ext }}$ 's in the range of $170-210^{\circ} \mathrm{C}$; $T_{\text {ext }}=170^{\circ} \mathrm{C}(\square), 190^{\circ} \mathrm{C}(\Delta), 200^{\circ} \mathrm{C}(\bullet)$ and $210^{\circ} \mathrm{C}(\triangle)$. The solid-line shows the tensile modulus for the SSCE of a PLLA/ PDLA cast film, ${ }^{21}$ which was consisted predominantly of $\alpha$-form crystals, at a $T_{\mathrm{ext}}=200^{\circ} \mathrm{C}$ were also included for comparison.

tallization proceeded during the drawing. With increasing in the $T_{\text {ext }}$, the formation of oriented sccrystals was induced significantly during drawing, concurrently with the deformation of the sc-crystals that initially existed within the cast film.

Figure 6 shows the room temperature tensile modulus vs. EDR for SSCE of a cast film ( $7 \mathrm{~d}$-film) at $T_{\text {ext }}$ 's $=170,190,200$ and $210^{\circ} \mathrm{C}$. The tensile modulus increased rapidly with EDR in a low EDR range, reaching a maximum value of 7-9.5 GPa at a higher EDR of 12-17, depending on the $T_{\text {ext }}$. At yet higher EDR, the tensile modulus decreased rapidly for SSCE at $T_{\text {ext }}$ 's $=190$ and $200^{\circ} \mathrm{C}$ due to the formation of flaws detected by an optical microscope. ${ }^{28}$ The maximum modulus of $9.5 \mathrm{GPa}$ was achieved by SSCE of a cast sc-film at a $T_{\text {ext }}=200^{\circ} \mathrm{C}$ and an EDR of 16. At the highest $T_{\text {ext }}$ of $210^{\circ} \mathrm{C}$, the modulus increased more slowly but steadily with EDR and the maximum modulus of $7.5 \mathrm{GPa}$ was achieved at the highest EDR of 19. This value was significantly lower than those of the samples prepared at $T_{\text {ext }}{ }^{\circ} \mathrm{s}=190$ and $200^{\circ} \mathrm{C}$. These results indicate that the efficiency of chain extension, orientation and crystallization induced by drawing was lower at the highest $T_{\text {ext }}$ of $210^{\circ} \mathrm{C}$ than that at lower $T_{\text {ext }}$ 's of 190 and $200^{\circ} \mathrm{C}$. To show the effect of initial morphology on the efficiency of draw, the tensile modulus measured as a function of EDR for a series of samples prepared by SSCE at a $T_{\text {ext }}$ of $200{ }^{\circ} \mathrm{C}$ from a cast film of an equimolar blend of PLLA/PDLA, which was consisted mainly of $\alpha$-form crystals and a small amount of sccrystals, is also shown in Figure $6 .{ }^{21}$ The important influence of the initial morphology was illustrated by the facts that for the SSCE at $200^{\circ} \mathrm{C}$, the tensile 


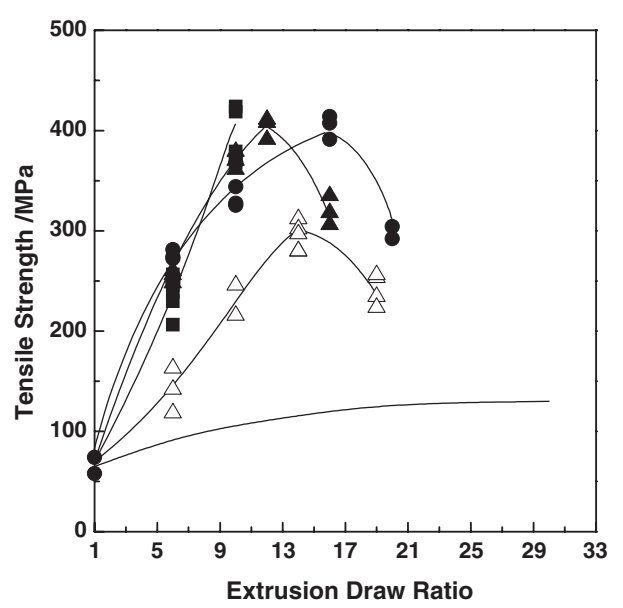

Figure 7. Tensile strength as a function of EDR for SSCE of a sc-film (7 d-film) at various $T_{\text {ext }}$ 's in the range of $170-210^{\circ} \mathrm{C}$. The symbols are the same as in Figure 6. The solid-line represent the tensile strength for the SSCE of a PLLA/PDLA cast film, ${ }^{21}$ which was consisted predominantly of $\alpha$-form crystals, at a $T_{\text {ext }}=200^{\circ} \mathrm{C}$ were also included for comparison.

modulus increased significantly more rapidly for the sc-film (7 d-film) with a $\Delta H_{\mathrm{f}}$ of $67 \mathrm{~J} / \mathrm{g}$ (crystallinity of $43 \%$ ) than for the film consisted predominantly of $\alpha$-form homo-crystals. A similar effect of the initial morphology on the efficiency of draw was also observed in the tensile strength vs. EDR as shown below.

Figure 7 shows the tensile strength $v s$. EDR for the same sets of samples as shown in Figure 6. Commonly, the strength rapidly increased with EDR in a lower EDR range, reaching a maximum value of 300-410 $\mathrm{MPa}$ at higher EDRs of 9-16, depending on the $T_{\text {ext }}$ 's. At yet higher EDR's the strength rapidly decreased with increasing EDR due to the formation of flaws. ${ }^{28}$ The maximum strength achieved was $410 \mathrm{MPa}$ for the SSCE at a $T_{\mathrm{ext}}=170^{\circ} \mathrm{C}$ and an $\mathrm{EDR}=10$, at a $T_{\mathrm{ext}}=190^{\circ} \mathrm{C}$ and an $\mathrm{EDR}=12$, and at a $T_{\text {ext }}=200{ }^{\circ} \mathrm{C}$ and an EDR $=16$. The elongation at break decreased with increasing EDR. For example, it decreased from $55 \%$ for the undrawn $7 \mathrm{~d}$ film, $21 \%$ for the sample wit an EDR of 6 and 13\% for the sample with an EDR of 20, both prepared at a $T_{\mathrm{ext}}=200^{\circ} \mathrm{C}$. In contrast to the SSCE of a highly crystalline sc-film used in this work, the tensile strength for the SSCE of a cast film of PLLA/PDLA at $200^{\circ} \mathrm{C}$, which was consisted predominantly of $\alpha$-form homo-crystals, increased only slightly with the EDR and the maximum achieved strength was $130 \mathrm{MPa}$ as shown in Figure 7. ${ }^{21}$

This lower efficiency of draw for the SSCE of a film consisting predominantly of $\alpha$-form homo-crystals at a $T_{\text {ext }}=200^{\circ} \mathrm{C}$ than for the SSCE of a highly crystalline sc-film at a $T_{\text {ext }}=200^{\circ} \mathrm{C}$ was due to the facts that the SSCE of the former proceeded in a liquid like state in which all of the $\alpha$-form crystals melted whereas the latter proceeded in the crystalline state where the sccrystals persisted.

In this study, the highest tensile modulus and strength achieved were $9.5 \mathrm{GPa}$ and $410 \mathrm{MPa}$, respectively. A few articles had reported the development of tensile modulus and strength of sc-fibers prepared by melt-spinning and/or drawing. As reported by Takasaki et al.,${ }^{19}$ their fiber with the highest sc-crystal content (crystallinity, $\chi_{\mathrm{c}}{ }^{\mathrm{sc}}=\sim 38 \%$ ) prepared by high-speed melt spinning, followed by annealing showed tensile modulus and strength of $\sim 4.0 \mathrm{GPa}$ and $200 \mathrm{MPa}$, respectively. Yamane et al. ${ }^{20}$ prepared an oriented sc-fibers $\left(\chi_{c}{ }^{s c}=\sim 40 \mathrm{wt} \%\right)$ by the combination of melt spinning of an amorphous fiber and cold drawing, followed by annealing. Their fibers had tensile modulus and strength of $4.7 \mathrm{GPa}$ and $335 \mathrm{MPa}$, respectively. In our previous paper on SSCE of a film of an equimolar blend of PLLA and PDLA, which consisted predominantly of $\alpha$-form crystals, the maximum achieved tensile modulus and strength were 5.0 GPa and $130 \mathrm{MPa}$, respectively. ${ }^{21}$ These previous results combined with the present results show that the most efficient draw was achieved by drawing of a highly crystalline sc-sample in the crystalline state at a temperature between the $T_{\mathrm{m}}$ 's of the homo-crystals $\left(\sim 180^{\circ} \mathrm{C}\right)$ and sc-crystal $\left(\sim 230^{\circ} \mathrm{C}\right)$.

Figure 8 shows the temperature dependence of the dynamic storage modulus $\left(E^{\prime}\right)$ and loss tangent $(\tan \delta)$ for an EDR series of sc-films measured at a frequency of $11 \mathrm{~Hz}$.

The data for a solvent cast $\alpha$-film of PLLA consisting of $\alpha$-form crystals (crystallinity, $\chi_{\mathrm{c}}{ }^{\alpha}=47 \mathrm{wt} \%$ ) and an oriented PLLA $\beta$-film consisting of $\beta$-crystals (crystallinity, $\chi_{\mathrm{c}}{ }^{\beta}=53 \mathrm{wt} \%$ ) prepared by SSCE of the PLLA $\alpha$-film at a $T_{\text {ext }}=170^{\circ} \mathrm{C}$ and an EDR of 16 were also shown for comparison. For the dynamic mechanical measurements, a PLLA sample with a higher $M_{\mathrm{w}}$ of $2.3 \times 10^{5}$, comparable to that of the PDLA used in this work, was used because the lower $M_{\mathrm{w}}$ PLLA $\left(M_{\mathrm{w}}=7.1 \times 10^{4}\right)$ used for the preparation of sc-samples exhibited a low ductility. ${ }^{29}$ The $\tan \delta$ peak at around $80^{\circ} \mathrm{C}$ corresponds to the $\alpha$-relaxation which is related to the glass transition of the polymers.

The undrawn PLLA film consisting of $\alpha$-crystals exhibited a sharp and strong $\tan \delta$ peak at around $80^{\circ} \mathrm{C}$ due to the $\alpha$-relaxation. Upon SSCE of this film at a $T_{\text {ext }}=170^{\circ} \mathrm{C}$ and an EDR of 16 , the $\alpha$-relaxation peak became broader and weaker due to the constraints imposed on the noncrystalline regions through the taut tie molecules formed by the destruction of initial crystals into smaller crystalline blocks arranged along the draw direction, as extensively discussed by Peterlin. ${ }^{30}$ A slight decrease in the amount of amor- 


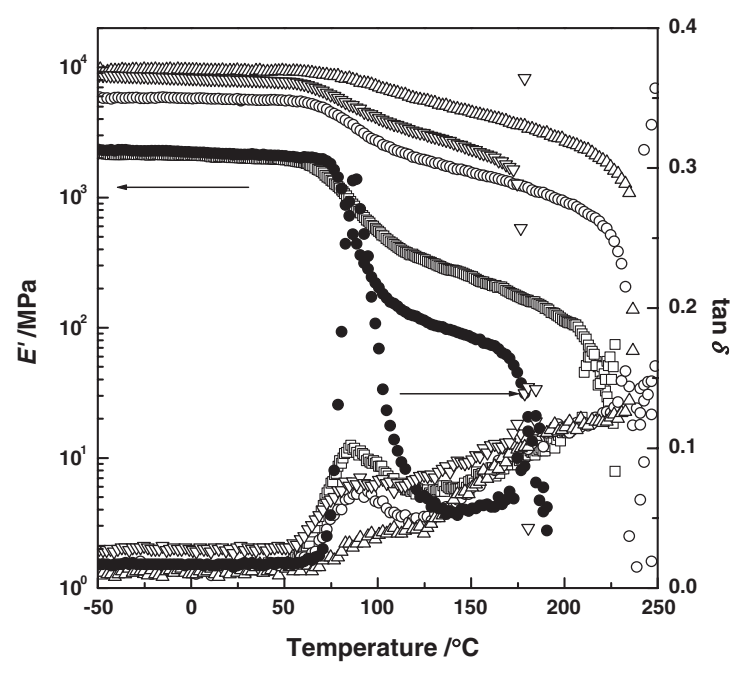

Figure 8. Temperature dependence of the dynamic Young's modulus $\left(E^{\prime}\right)$ and the loss tangent $(\tan \delta)$ measured at $11 \mathrm{~Hz}$ for the starting sc-film $(\square)$ and drawn products with EDR $=6(\bigcirc)$ and $16(\triangle)$ prepared at a $T_{\text {ext }}=210^{\circ} \mathrm{C}$. Data $(\bullet)$ of a PLLA cast film consisting of $\alpha$-crystals $\left(\chi_{\mathrm{c}}=47 \mathrm{wt} \%\right)$ and its extrusiondrawn product with an EDR of 16 consisting of oriented $\beta$-crystals $(\nabla)$ are also shown for comparison. Since the lower $M_{\mathrm{w}}$ PLLA used for the preparation of sc-samples exhibited a low ductility, the PLLA samples prepared from a higher $M_{\mathrm{w}}$ of $2.3 \times 10^{5}$ was used for the dynamic mechanical measurements.

phous chains, corresponding to the small increase in crystallinity upon the drawing (from 47 to $53 \mathrm{wt} \%$ ) also contributed to the lowering of the peak intensity.

The undrawn sc-film consisting of randomly oriented sc-crystals exhibited a broad $\tan \delta$ peak at around $80^{\circ} \mathrm{C}$ due to the $\alpha$-relaxation. Upon SSCE of this sc-film at $200^{\circ} \mathrm{C}$, although the $\tan \delta$ peak stayed at a constant temperature of $80^{\circ} \mathrm{C}$, the peak intensity decreased significantly with increasing EDR and a film with an EDR of 16 showed no clear peak due to the $\alpha$-relaxation as seen in Figure 8.

The $\tan \delta$ peak temperatures of these samples were $\sim 80^{\circ} \mathrm{C}$ and not affected by the crystal forms and by the EDR of samples. However, it is interesting to note that although both the as-cast sc-film and the as-cast $\alpha$-film of PLLA had a comparable crystallinity of $\sim 45 \mathrm{wt} \%$ and exhibited the glass transition at the same temperature of $\sim 65^{\circ} \mathrm{C}$ as determined by DSC measurements, these two samples exhibited significantly different relaxation behavior. The former exhibited significantly broader and weaker $\tan \delta$ peak than that for the latter. These facts suggest that the noncrystalline chains of the sc-film received significant constraints from the crystallites whereas those of $\alpha$-film of PLLA were highly relaxed, although both of them were prepared by the solvent casting.

Generally, the constrained amorphous chains are expected to be relaxed when the sample was exposed to a higher temperature. However, although the oriented samples of sc-film and $\beta$-film with an EDR of 16 had a similar crystallinity of $56 \pm 3 \mathrm{wt} \%$, the former prepared at a higher $T_{\text {ext }}$ of $200{ }^{\circ} \mathrm{C}$ showed a significantly weaker $\alpha$-relaxation peak than the latter prepared at a lower $T_{\text {ext }}$ of $170^{\circ} \mathrm{C}$. These results indicate that the segmental mobility in noncrystalline regions, associated with the glass transition, was significantly suppressed in the samples consisting of sc-crystals. Tsuji et al. ${ }^{31,32}$ has reported that the formation of spherulites was suppressed in sc-form films, whereas large-sized spherulites with radii of $100-1000 \mu \mathrm{m}$ formed for PLLA and PDLA films consisting of $\alpha$ form. Therefore, the remarkable differences in the $\alpha$ relaxation behavior around $T_{\mathrm{g}}$ between the sc-films and $\alpha$-from homo-polymer films may be ascribed to the existence of tiny sc-crystals for the former, which might act as the junction points suppressing the segmental motions of the amorphous chains as was observed upon the drawing of an $\alpha$-film of PLLA (see Figure 8).

Reflecting the different $T_{\mathrm{m}}$ 's and the characteristic relaxation behaviors of sc-films and PLLA films, the temperature dependence of $E^{\prime}$ for these samples are significantly different. A closer inspection of the $\mathrm{E}^{\prime}$ data in Figure 8 revealed that the onset of reduction in the $\mathrm{E}^{\prime}$ value for the undrawn PLLA film started at a slightly higher temperature than that for other samples. This is likely related to the higher $M_{\mathrm{w}}$ of the PLLA sample used for the dynamic mechanical measurements and its specific relaxation behavior characterized by the sharp and strong $\tan \delta$ peak due to the $\alpha$-relaxation.

The $E^{\prime}$ value at a given temperature increased with EDR for drawing of both sc-films and PLLA films. At the same EDR, the $E^{\prime}$ values of the sc-films prepared at a $T_{\text {ext }}$ of $200^{\circ} \mathrm{C}$ and the PLLA films prepared at a $T_{\text {ext }}$ of $170^{\circ} \mathrm{C}$ were comparable below the onset of $\alpha$-relaxation. At temperatures above the onset of $\alpha$-relaxation, however, the sc-film showed a significantly higher $E^{\prime}$ value than that for the PLA film having the same EDR as the sc-film. For example, the sc-film and the PLLA film with an EDR of 16 exhibited the same $E^{\prime}$ value of $9.5 \mathrm{GPa}$ at room temperature and 3 and $4.5 \mathrm{GPa}$, respectively, at $150^{\circ} \mathrm{C}$. Even at $200^{\circ} \mathrm{C}$, $\sim 20^{\circ} \mathrm{C}$ above the $T_{\mathrm{m}}$ of PLLA, the sc-film with an EDR of 16 kept a $E^{\prime}$ value of $3 \mathrm{GPa}$, reflecting the higher $T_{\mathrm{m}}$ and the weak $\alpha$-relaxation intensity of this sample. Thus, the sc-film with a high chain orientation and crystallinity exhibited an excellent heat-resistance until the melting occurred at around $230^{\circ} \mathrm{C}$. Moreover, the fact that no crystalline relaxation was present in the sc-films below the $T_{\mathrm{m}}$ also contributed the high heat-resistance. 


\section{CONCLUSION}

A film consisting of only sc-crystals was prepared from an equimolar blend of PLLA and PDLA. The sc-film was uniaxially drawn by SSCE and the development of oriented sc-morphology and mechanical properties were studied. The mechanical properties of drawn films depended on the $T_{\text {ext }}$. The optimum draw temperature giving the highest draw and mechanical properties was $200^{\circ} \mathrm{C}$. The maximum achieved tensile modulus and strength were $9.5 \mathrm{GPa}$ and $410 \mathrm{MPa}$, respectively, at room temperature for the sample with an EDR $=16$ prepared by SSCE of a highly crystalline sc-film at a $T_{\mathrm{ext}}=200^{\circ} \mathrm{C}$. Such a highly drawn film showed a high chain orientation function of $f_{\mathrm{c}}=0.993$ and crystallinity of $59 \mathrm{wt} \%$. Those values were the highest among ever reported for the fibers and films consisting of only sc-crystals. Furthermore, the sc-film with an EDR of 16 exhibited an excellent thermal stability as evaluated by the $E^{\prime}$ measured as a function of temperature; $E^{\prime}=9.5 \mathrm{GPa}$ at room temperature, $7 \mathrm{GPa}$ at $100^{\circ} \mathrm{C}$ and $3 \mathrm{GPa}$ at $200^{\circ} \mathrm{C}$ which is about $20^{\circ} \mathrm{C}$ above the $T_{\mathrm{m}}$ of PLLA homo-polymer.

Acknowledgment. This work was partly supported by an Industrial Technology Research Grant Program in '05 (Project No. 05A52002c) from New Energy and Industrial Technology Development Organization (NEDO) of Japan.

\section{REFERENCES}

1. Y. Ikada and H. Tsuji, Macromol. Rapid Commun., 21, 117 (2000).

2. H. Tsuji and Y. Ikada, in "Polylactides," Koubunshi Kankoukai Inc. Kyoto, 1997.

3. H. Tsuji and Y. Ikada, Macromol. Chem. Phys., 197, 3483 (1996).

4. T. Shimamoto, T. Oka, M. Adachi, S. H. Hyon, K. Nakayama, and A. Kaito, U. S. Patent 5431652 (1995).

5. G. Perego, G. D. Cella, and C. Bastioli, J. Appl. Polym. Sci., 59, 37 (1996).

6. S. H. Hyon, F. Jin, K. Jamshidi, S. Tsutsumi, and T. Kanamoto, Macromol. Symp., 197, 355 (2003).

7. J. W. Leenslag and A. J. Pennings, Polymer, 28, 1695 (1987).

8. J. W. Leenslag and A. J. Pennings, Polym. Commun., 28, 92
(1987).

9. H. Okuzaki, I. Kubota, and T. Kunugi, J. Polym. Sci., Part B, 37, 991 (1999).

10. W. Hoogsteen, A. R. Postema, A. J. Pennings, G. Brinke, and P. Zugenmaier, Macromolecules, 23, 634 (1990).

11. D. Sawai, K. Takahashi, T. Imamura, K. Nakamura, T. Kanamoto, and S. H. Hyon, J. Polym. Sci., Polym. Phys. Ed., 40, 95 (2002).

12. D. Sawai, K. Takahashi, A. Sasashige, K. Nakamura, T. Kanamoto, and S. H. Hyon, Macromolecules, 36, 3601 (2003).

13. T. Okihara, M. Tsuji, A. Kawaguchi, K. J. Katayama, H. Tsuji, S. H. Hyon, and Y. Ikada, Macromol. Sci., Phys., B30, 119 (1991).

14. D. Brizzolara, H. J. Cantow, K. Diederichs, E. Keller, and A. J. Domb, Macromolecules, 29, 191 (1996).

15. K. Fukushima and Y. Kimura, Polym. Int., 55, 626 (2006).

16. K. Fukushima, K. Sogo, S. Miura, and Y. Kimura, Macromol Biosci., 4, 1021 (2004).

17. H. Tsuji, S. H. Hyon, and Y. Ikada, Macromolecules, 24, 5651 (1991).

18. H. Tsuji, S. H. Hyon, and Y. Ikada, Macromolecules, 24, 5657 (1991).

19. M. Takasaki, H. Ito, and T. Kikutani, J. Macromol. Sci., Phys., B42(3\&4), 403 (2003).

20. Y. Furuhashi, Y. Kimura, N. Yoshie, and H. Yamane, Polymer, 47, 5965 (2006).

21. D. Sawai, M. Tamada, T. Yokoyama, T. Kanamoto, S.-H. Hyon, and S. Moon, Seni Gakkaishi, 63, 1 (2007).

22. H. Tsuji, Y. Ikada, S. H. Hyon, Y. Kimura, and T. Kitao, J. Appl. Polym. Sci., 51, 337 (1994).

23. P. D. Griswold, A. E. Zachariades, and R. S. Porter, Polym. Eng. Sci., 18, 861 (1978).

24. F. W. Fischer, H. J. Sterzel, G. Wegner, and Z. Z. Kolloid, Polym, 251, 980 (1973).

25. D. Sawai, Y. Tsugane, M. Tamada, T. Kanamoto, S.-H. Hyon, and S. Moon, J. Polym. Sci., Polym. Phys. Ed., in press.

26. L. E. Alexander, in "X-ray Diffraction Methods in Polymer Science," John Wiley \& Sons, New York, 1969.

27. G. L. Loomis, J. R. Murdoch, and K. H. Gardner, Polym. Prepr. (Am. Chem. Soc., Div. Polym. Chem.), 31(2), 55 (1990).

28. D. Sawai, D. Watanabe, N. Morooka, H. Kuroki, and T. Kanamoto, J. Polym. Sci., Polym. Phys. Ed., 44, 3369 (2006).

29. D. Sawai, T. Yokoyama, T. Kanamoto, M. Sungil, S.-H. Hyon, and L. P. Myasnikova, Macromol. Symp., 242, 93 (2006).

30. A. Peterlin, Colloid Polym. Sci., 265, 357 (1987).

31. H. Tsuji and Y. Ikada, Polymer, 40, 6699 (1999).

32. H. Tsuji, Polymer, 41, 3621 (2000). 